\title{
Reflexos do estresse infantil no processo de ensino e aprendizagem: possibilidades de
}

\section{intervenção pedagógica}

\author{
Reflections of children's stress in the teaching and learning process: possibilities of pedagogical \\ intervention
}

Reflexiones del estrés infantil en el proceso de enseñanza y aprendizaje: posibilidades de intervención pedagógica

Recebido: 11/08/2021 | Revisado: 16/08/2021 | Aceito: 18/08/2021 | Publicado: 22/08/2021

\author{
Sirlene Zancanela da Silva \\ ORCID: https://orcid.org/0000-0002-9138-7647 \\ Secretaria Municipal de Educação de Maringá, Brasil \\ E-mail: sirlenezancsilva@gmal.com \\ Daiane Letícia Boiago \\ ORCID: https://orcid.org/0000-0001-8381-8796 \\ Centro Universitário Metropolitano de Maringá, Brasil \\ E-mail: daianeleticia@gmail.com \\ Vânia de Fátima Matias de Souza \\ ORCID: https://orcid.org/0000-0003-4631-1245 \\ Universidade Estadual de Maringá, Brasil \\ E-mail: vfmatias@gmail.com \\ Ana Luiza Barbosa Anversa \\ ORCID: https://orcid.org/0000-0003-4363-3433 \\ Universidade Estadual de Maringá, Brasil \\ Centro Universitário Metropolitano de Maringá, Brasil \\ E-mail: ana.beah@gmail.com
}

\begin{abstract}
Resumo
O presente estudo, de cunho bibliográfico, tem como objetivo analisar como o estresse infantil se reflete no processo de ensino e de aprendizagem, em especial nos primeiros anos da educação básica. O estresse é uma reação física e psicológica que pode acometer os indivíduos, de forma negativa ou positiva, em qualquer idade, inclusive na infância. A realização desta pesquisa provém da inquietação em compreender a relação entre o estresse e o desempenho escolar dos alunos, buscando identificar as causas e sintomas provenientes do estresse infantil. Constatou-se que o estresse infantil pode interferir no processo de desenvolvimento do sujeito, influenciando o processo de socialização e aprendizagem, uma vez que reduz a concentração e autoestima, além de minimizar as ações de interação com o mundo. A intervenção docente é importante no processo de identificação de quadros do transtorno do estresse, uma vez que esse pode vir a oferecer bases e auxílio para que os alunos se desenvolvam e lidem com as situações estressoras às quais estão submetidos. Frente ao exposto, reforça-se a importância de se perceber, o quanto antes, os sintomas de estresse apresentados pelas crianças, para que haja a intervenção de modo a auxiliar a superação dessas dificuldades e evitar que consequências cognitivas, emocionais e até mesmo físicas severas, cabendo ao professor oportunizar um ambiente harmonioso, que permita aos alunos aprenderem de forma tranquila e significativa, reduzindo as fontes estressoras que são as consequências do estresse infantil.
\end{abstract}

Palavras-chave: Estresse; Infância; Aprendizagem.

\begin{abstract}
This study aims to analyze how child stress is reflected in the teaching and learning process, especially in the early years of basic education. Stress is a physical and psychological reaction that affects individuals, negatively or positively, at any age, including children. This research stems from the concern to understand the relationship between stress and students' school performance, analyzing the causes and symptoms arising from childhood stress. Child stress can interfere with the child's development, socialization and learning process, as it reduces the learner's concentration and self-esteem, as well as their interaction with the surrounding world. Thus, the teaching intervention is important in the process of identifying stress disorder pictures, as it may provide the basis and help for students to develop and deal with the stressful situations to which they are subjected. In view of the above, the importance of understanding the stress symptoms presented by children early is reinforced, so that adults can intervene to help overcome these difficulties and prevent severe cognitive, emotional and even physical consequences, and it is up to the teacher. Provide a harmonious environment that allows students to learn in a meaningful and peaceful way, reducing the stressful sources and consequences of child stress.
\end{abstract}

Keywords: Stress; Childhood; Learning. 


\begin{abstract}
Resumen
Este estudio bibliográfico tiene como objetivo analizar cómo el estrés infantil se refleja en el proceso de enseñanza y aprendizaje, especialmente en los primeros años de educación básica. El estrés es una reacción física y psicológica que puede afectar a las personas, de forma negativa o positiva, a cualquier edad, incluida la infancia. La concreción de esta investigación surge de la inquietud por comprender la relación entre el estrés y el desempeño escolar de los estudiantes, buscando identificar las causas y síntomas del estrés infantil. Se encontró que el estrés infantil puede interferir con el proceso de desarrollo del sujeto, influyendo en el proceso de socialización y aprendizaje, ya que reduce la concentración y la autoestima, además de minimizar las acciones de interacción con el mundo. La intervención del profesorado es importante en el proceso de identificación de las condiciones del trastorno por estrés, ya que puede proporcionar bases y ayudar a los estudiantes a desarrollar y afrontar las situaciones estresantes a las que se ven sometidos. En vista de lo anterior, se refuerza la importancia de darse cuenta, lo antes posible, de los síntomas de estrés que presentan los niños, por lo que se interviene con el fin de ayudar a superar estas dificultades y prevenir graves consecuencias cognitivas, emocionales e incluso físicas, Corresponde al docente crear un ambiente armonioso que permita a los estudiantes aprender de manera calmada y significativa, reduciendo las fuentes de estrés que son las consecuencias del estrés infantil.
\end{abstract}

Palabras clave: Estrés; Infancia; Aprendiendo.

\title{
1. Introdução
}

O presente artigo apresenta como temática a discussão sobre os reflexos do estresse infantil no processo de aprendizagem e desenvolvimento da criança, buscando explicitar possibilidades de práticas pedagógicas que estimulem a aprendizagem em crianças que apresentam estresse no contexto escolar. Nosso objetivo é analisar como o estresse infantil refletese no processo de ensino e de aprendizagem, em especial nos primeiros anos da educação básica.

Estudar as relações entre saúde e educação é fundamental para o aperfeiçoamento da prática pedagógica do professor, em especial na educação infantil e anos iniciais do ensino fundamental. Trata-se de uma temática ainda pouco explorada no Brasil e que se faz de suma importância para a compreensão das dificuldades de aprendizagem apresentadas ao longo do processo de ensino formal.

O estresse pode afetar pessoas de todas as idades e contextos. Nos adultos esse transtorno está relacionado com as demandas de trabalho, juntamente com as responsabilidades de decidir algo importante e encargos do dia a dia. Já nas crianças pode estar associado a problemas de ordem familiar, social e/ou educacional, e esse estado de estresse pode afetar a maturação do eixo hipotálamo-pituitária-adrenal e se refletir nas respostas dadas aos estímulos externos e por consequência no processo de ensino e de aprendizagem (Souza et al.,2020).

Molina (1996) aponta que o estresse infantil decorre de um fator estressor de ordem física, social, psicológica, econômica e ambiental, que quando mal administrado resulta em sentimento de frustração, sensação de impotência, instabilidade emocional, insegurança, estado de mal-estar e desconforto físico e psicológico. Frente a isso, no cenário escolar é preciso lidar com as condutas do processo de ensino e aprendizagem de forma organizada, visando o desenvolvimento integral da criança (cognitivo, afetivo, sentimental, emocional) e ações que gerem prazer, empatia, respeito, etc. (da Silva Braga; Rodrigues, 2020).

Lipp (1991) indica que a rotina escolar e de afazeres pessoais, se mal planejados e monitorados, podem se colocar como um agente estressor, que resulta em sensações físicas e psicológicas, podendo tornar-se uma fonte estressora excessiva e levar a problemas graves de saúde. Ao indicar a rotina escolar como um agente estressor Elking (2004), ressalta que a rotina rígida, préestabelecida e a demanda de novos conteúdos, conhecimentos e aprendizagem, se coloca como agente estressor, gerando na criança desafios de múltiplas demandas e diferentes sensações de convívio, que quando mal administrados e respeitados pode resultar em graus elevados de estresse.

Esse grau de estresse pode refletir-se diretamente no processo de ensino e de aprendizagem, compreendido como interações comportamentais entre professores e alunos, no qual as "emoções desempenham papel fundamental, pois, juntamente com o aspecto cognitivo, são capazes de mediar e consolidar a aprendizagem efetiva" (Costa, 1995, p. 4). Deste modo, o controle das emoções pode atuar diretamente sobre a combinação de objetivos, conteúdos, métodos e na forma como os conteúdos são 
organizados e assimilados, resultando em conhecimentos, habilidades, hábitos e no desenvolvimento das capacidades cognoscitivas.

\section{Metodologia}

Para se atingir o objetivo proposto, a presente pesquisa assume-se como básica, descritiva de cunho bibliográfico (Gil, 2002; Pandanov; Freitas, 2013), uma vez que esse tipo de pesquisa possibilita captar a informação desejada de maneira imediata, por meio da leitura de pesquisas já realizadas na temática investigativa. A característica bibliográfica é um método científico para busca e análise de artigos e livros de uma determinada área da ciência aprimorando descobertas de intuições e ideias (Conforto; Amaral; Silva, 2011).

A pesquisa foi realizada junto a livros e artigos online, sem limite de data a partir das palavras-chave estresse, educação infantil e aprendizagem. Para melhor compreensão e discussão dos resultados encontrados o artigo está estruturado em três momentos: O primeiro abordará o estresse e seus reflexos na infância, visando definir o que é o estresse e, principalmente, as definições do estresse infantil. No segundo momento discutirá o processo de ensino e de aprendizagem e as possíveis relações com o estresse infantil. Por fim, o terceiro momento analisará o papel do professor no processo e de ensino aprendizagem.

\section{Resultados e Discussão}

\subsection{Compreendendo o estresse e seus reflexos na infância}

O estresse é uma reação do organismo que envolve componentes físicos e/ou psicológicos causados por alterações psicofisiológicas que ocorrem quando a pessoa se confronta com situações que a "irrite, amedronte, excite ou confunda, ou mesmo que a faça imensamente feliz" (Lipp 2002, p. 52). A autora associa o estresse a um estado de tensão que causa uma ruptura no equilíbrio interno do organismo, causando no indivíduo um considerável desgaste e utilização de reserva de energia física e mental.

Ferreira (2010, p. 298) conceitua o estresse como o "conjunto de reações do organismo a agressões de origens diversas, capazes de perturbar o equilíbrio interno". O dicionário Aurélio (2010), apresenta o estresse como o conjunto de reações do organismo a agressões de ordem física, psíquica, infecciosa, capazes de perturbar a homeostase corporal. Na psicologia, o estresse é entendido como estado em que se encontra a pessoa submetida a uma excessiva carga emocional, que acaba por neutralizar sua capacidade de resolver problemas e amenizar tensões (Yepes, 2002).

Em geral o organismo humano funciona em perfeita sintonia interior, os órgãos trabalham em colaboração uns com os outros, sendo que em período de estresse esse funcionamento é afetado, e "cada órgão passa a trabalhar em um ritmo [...] Por exemplo, o coração bate muito rápido, mas o estômago demora mais para digerir o alimento o que gera uma quebra no equilíbrio interior" (Lipp, 2000, p.17).

A autora destaca que o estresse em si não é considerado uma doença, porém quando a homeostase é afetada ocorre um desconforto mental e físico, ocasionado de maneira intensa e prolongada, pode enfraquecer o organismo, causando condições que propicia sintomas indesejáveis e possíveis doenças, podendo manifestar-se tanto no corpo quanto na mente. Molina (1996) coloca que o estresse decorre de elementos estressores de ordem física, social, psicológica, econômica e/ou ambiental, que geram tensão ou força no organismo, o que pode induzir sentimento de frustração, insegurança, instabilidade emocional, sensação de impotência e mal estares de ordem física e psicológica.

Esse desequilíbrio afeta o indivíduo causando um considerável desgaste e utilização de reservas de energia física e mental, deste modo pessoas que têm em suas vidas uma fonte de estresse grande e permanente, como uma ocupação complicada ou uma situação familiar conflituosa, que constantemente afeta o seu equilíbrio interior, nesses casos o "processo do estresse se constitui em um ciclo de altos e baixos, em que a pessoa consegue, com esforço, restabelecer o equilíbrio e este é quebrado 
novamente" (Lipp, 2002, p.16).

O estresse produz modificações na estrutura e na composição química do corpo, os distúrbios psicológicos mais comuns são: depressão, enurese, dificuldades de relacionamento, comportamento agressivo, ansiedade, choro excessivo, gagueira, dificuldades escolares, pesadelos, irritabilidade e insônia. Os distúrbios físicos são: asma, dores de barriga, dores de cabeça, ânsia de vômito, doenças dermatológicas, entre outras (Sisto; Martinelli, 2006).

Com relação ao estresse infantil, Lipp (2000) destaca que inevitavelmente, toda criança enfrentara situações de estresse logo nos primeiros anos de vida e que muitas vezes poderá alcançar níveis muito elevados, para sua capacidade de desenvolvimento emocional, intelectual e afetivo, ultrapassando sua disposição ainda imatura para lidar com situações conflitantes. Os efeitos do estresse na infância são ainda mais perigosos do que na idade adulta, pois interferem na sua capacidade de reter informações implícitas em relações afetivas e sociais, o que pode resultar em problemas de comportamento, relacionamento social, violência de forma verbal ou física, autoestima baixa, ataques de nervosismo e falta de autonomia. Deste modo, crianças com quadros de estresse podem se tornar adultos indiferentes, sem motivação, insensíveis e sem criatividade que também não saberão desenvolver habilidades e estratégias para relacionar-se (Lipp 2002).

A escola coloca-se como um dos locais de socialização da criança e a maneira como a criança identifica-se nesse contexto e é identificada pelos demais colegas e professores pode se refletir na identidade do sujeito e, também no seu estado de alerta. Quando esse reconhecimento é negativo ou abaixo de suas expectativas a criança pode apresentar baixa autoestima e capacidade de concentração, deixando-a estressada e desestimulada e por consequência reduzindo seu rendimento ao longo do processo de aprendizagem (Lipp, 2002).

Entende-se que os fatores geradores mais comuns do estresse infantil estão no ambiente familiar e escolar, essas condições contribuem para o desencadeamento de doenças que podem afetar o desenvolvimento emocional da criança, atrapalhando a vida escolar e pessoal (Lipp 2002). A autora destaca que os sintomas físicos mais comuns são: dor de barriga, diarreia, tique nervoso, dor de cabeça, náusea, hiperatividade, enurese noturna, gagueira, tensão muscular, ranger de dentes, falta de apetite, mãos frias e suadas. Já os sintomas psicológicos são: terror noturno, introversão súbita, medo ou choro excessivo, agressividade, impaciência, pesadelos, ansiedade, dificuldades interpessoais, desobediência, insegurança e hipersensibilidade.

A literatura pertinente ao estudo do estresse infantil, tal como apresenta Lipp (1991), tem demonstrado que o ambiente escolar pode ser um fator de desencadeamento do estresse, bem como, que esse transtorno pode afetar diretamente o processo de aprendizagem da criança, como veremos a seguir.

\subsection{O processo de ensino e de aprendizagem: possíveis relações com o estresse infantil}

A pedagogia possui um desafio constante de promoção da aprendizagem e "desenvolvimento de competências e habilidades de maneira significativa e duradoura no âmbito escolar" (Gonçalves; Canal; Missawa, 2016, p. 151). Para Saviani (1985) o pedagogo é o profissional que possibilita e facilita o acesso à cultura e desta maneira possibilita formação cultural que coincide com a formação humana.

Durante a infância a criança está inserida no método de aprendizagem formal, por meio da aquisição de habilidades básicas de leitura, escrita e cálculo, sobre as quais se apoiarão todos os conhecimentos a serem aprendidos e posteriormente utilizados (Coll; Bolea, 1996).

Na organização da educação brasileira, o ensino regular formal deve ser obrigatório para crianças a partir dos 4 anos de idade (Brasil, 1996). Nesse período, os processos afetivos e a estabilidade emocional podem refletir sobre o processo de aprendizagem, uma vez que segundo Fuentes (2014) uma criança com problemas emocionais pode não apresentar linearidade no processo de ensino e aprendizagem resultando em situações de oposição e negativismo.

Além disso, Lipp et al. (1991) apontam que por ser um dos primeiros lugares de socialização da criança para além da 
família, a escola precisa se atentar a ações de adaptação da criança ao contexto, favorecendo sentimentos positivos e interações sociais. A aprendizagem e socialização entre os pares devem ser apresentadas como mais importante do que a execução de tarefas e a obtenção de resultados.

Para realizar uma tarefa, a emoção experimentada pelo aluno depende das características do conteúdo e metodologia utilizada pelo professor, sendo assim o aluno só aprende de forma significativa quando atribui sentido ao conteúdo e sinta-se motivado, de tal modo a aprendizagem deverá ser interessante e atrativa para que o educando se coloque ativamente em um processo de atribuição e significados, interiorizando o conteúdo proposto e aproprie-se deste conhecimento (Neves; Carvalho, 2006, de Oliveira et al.,2020).

De acordo com a neurociência das emoções a aprendizagem é um ato que envolve a plasticidade cerebral, definida como a "capacidade do cérebro de modificar ou modular seu funcionamento de acordo com as experiências e com o meio ambiente" (Dos Santos, 2015, p.5). O cérebro não é uma estrutura rígida, mas sim moldável pelas experiências de aprendizado, considerando assim, quanto mais novo o indivíduo, em termos de idade cronológica, maior será a sua capacidade de aprendizado tornando-se mais difícil no decorrer do tempo, dificultando assim o aprendizado na fase idosa, pois nesta fase o cérebro apresentará maior a rigidez e daí à importância das experiências de aprendizado na infância e do investimento em aprendizagem nessa fase (Costa, 1995).

A neurociência contemporânea é categórica ao afirmar que não existe memória sem emoção, em que o aluno aprende efetivamente a partir de emoções positivas, desta maneira se o ambiente ou o processo de ensino encontra-se sob ameaças, pressão ou excesso de cobranças, ou se ele é pouco valorizado na escola ou em casa, pode ocasionar na criança emoções negativas, dificultando o processo de aprendizagem. $\mathrm{O}$ aluno aprende melhor quando o conteúdo se encaixa nas suas experiências cotidianas, por ocasionar significado algo que ele consiga utilizar em sua vida, considerando nesse caso emoções positivas, sendo assim percebe-se que o impacto das emoções pode ser capaz de modificar a aprendizagem (Tomaz; Giugliano, 1997).

De acordo com Lipp (2000) há algumas décadas iniciava-se a fase de escolarização por volta dos sete anos de idade, hoje o contato da criança com meio externo ocorre muito mais precocemente, por meio da educação infantil, podendo ser iniciada, desde os primeiros meses de vida, em geral assim que acaba a licença a maternidade e as mães precisam retornar ao mercado de trabalho. De acordo com a Lei de Diretrizes e Bases da Educação Nacional (LDBEN) 9.394/1996:

Art. 29. A educação infantil, primeira etapa da educação básica, tem como finalidade o desenvolvimento integral da criança de até cinco anos, em seus aspectos físico, psicológico, intelectual e social, complementando a ação da família e da comunidade.

Art. 30. A educação infantil será oferecida em: I - creches, ou entidades equivalentes, para crianças de até três anos de idade; II - pré-escolas, para as crianças de 4 (quatro) a 5 (cinco) anos de idade (BRASIL, 1996, p. 22).

Lipp (2002) ressalta ainda que o sistema educacional, traz contribuições pedagógicas para a formação da criança, que interage mais precocemente com outras crianças e se socializa mais cedo, desenvolvendo suas habilidades por meio de estímulos de forma mais produtiva. No entanto, um sistema de cobrança excessivo em junção a precocidade da relação entre a criança e o meio que ela vive, e ter que se submeter a horários para acordar, brincar, alimenta-se, dormir, é uma novidade, que quando é imposta de maneira pouco natural pode provocar ansiedade na criança, podendo provocar desvios pedagógicos, familiares ou escolares, as quais poderão tornar-se fontes geradoras de estresse.

Os aspectos afetivos e emocionais têm um papel indispensável no processo de desenvolvimento e construção do conhecimento do aluno. A relação afetiva modifica o processo de aprendizagem do aluno, podendo ser uma forte aliada em situações de desconforto e estresse por parte das crianças (Nery, 2003; Wallon, 2007).

O incentivo, a percepção e a prática do professor conduz a esse importante vínculo. Desta maneira, o conceito sobre 
afetividade faz relação principalmente com a conduta do ser humano na sociedade, direcionando como as pessoas relacionamse. Desta maneira a relação afetiva deve estar relacionada à infância e em todos os níveis, e em especial na Educação Infantil, pois trata-se de uma fase de maior desenvolvimento da personalidade da criança.

Para Tunes (2005), a relação afetiva da criança mediante ao meio onde ela vive, dentro e fora do ambiente escolar, constrói seu ser levando em consideração que a criança fica conectada o tempo todo ao ambiente onde ela se faz presente, percebendo as relações do mundo adulto a sua volta e manifesta-se.

A formação da memória no processo de aprendizagem ocorre mediante o uso de uma variedade de estímulos sensoriais visual, auditivo, tátil, olfativo, gustativo, etc. Para assim gerar emoção, expectativa, curiosidade e criatividade, ocasionando em maior capacidade e aprofundamento da percepção (Bartholomeu; Sisto; Rueda, 2006).

Em sala de aula esta tarefa torna-se ainda mais difícil para os professores perceber quando a criança está passando por esse desconforto infantil, sendo prejudicado por estar com problemas emocionais graves (Lipp 2002), podendo interferir na sua capacidade de reter informações implícitas, relações afetivas e sociais dificultando assim no aprendizado.

De acordo com Nascimento, Campos e Coelho (2011), a criança aprende por meio da interação e socialização com seus pares, por isso práticas mais lúdicas que trabalham a imaginação, criatividade, atenção e sociabilidade são mais enfatizadas na educação infantil (Kraemer, 2010). Com essa conduta, conforme Gonçalves; Canal; Missawa (2016) é possível trabalhar com o coletivo sem se esquecer das individualidades, adotando estratégias que tornem o ambiente motivador, para que o aluno se sinta bem ao longo do processo de aprendizagem e sinta-se participe das ações propostas no ensino formal.

\subsection{O papel do professor na mediação pedagógica do estresse infantil}

Diferentes situações correm no dia a dia em ambiente escoar, muitas vezes expondo os alunos em condição de estresse excessivo e suas consequências. Nesse sentido, o ideal seria que medidas preventivas fossem adotadas por parte das escolas, trabalhando as dificuldades dos alunos de maneira que possa ajudá-los a diminuir e até mesmo manejar o estresse de forma favorável ao desenvolvimento da criança.

Para Lipp (2000, p. 142) “diversos estudos indicam medidas preventivas que possam ser utilizadas nas escolas, pela direção e pelos professores". Vários recursos e medidas podem ser utilizados em sala de aula pelo professor para auxiliar os alunos no controle do estresse, sendo eles: Primeiramente o professor deve cuidar de seu próprio estresse, sabendo que um professor estressado pode contagiar seus alunos. Cabe ao professor ser paciente e valorizar o diálogo o professor deve fornecer instruções claras e precisas, elogiar as crianças sempre que possível, pois elogio é sempre gratificante e serve como estímulo.

Nesta fase de desenvolvimento o professor deve esforçar-se para conhecer cada um de seus alunos, lembra-los pelo nome, evitar sobrecarregar os mesmos de atividades, pois quando excesso elas podem se tornar aversivas. Assim estimular cada criança a superar suas dificuldades, sabendo elogiar seu esforço mesmo que o sucesso não tenha sido plenamente atingido.

O professor deve evitar gritos em sala de aula, pois os mesmos representam descontrole, tentar estabelecer um abito de sucesso entre os alunos com mais dificuldade, dar-lhes questões mais "fáceis" com certeza que eles responderão, motivando-os para tarefas mais complexas, incentivar a colaboração entre os educandos, lembrando que a ajuda mútua pode melhorar o desempenho da classe, permitindo que os alunos colaborem uns com os outros, pois quando mais eu ensino eu aprendo (FREIRE, 1996). Respeitar a individualidade de cada aluno, o professor deve lembrar-se de que cada um é um ser unifico e cada um aprende de acordo com seu tempo e maturação, evitar competição negativa entre as crianças, pois eles precisam aprender a colaborar entre si e sentir prazer com conquistas dos colegas (Lipp, 2000).

Uma relação cultivada de afeto e respeito entre professor/a e aluno/a acarretará a confiança e segurança que o aluno terá em superar suas dificuldades de aprendizagem e até mesmo no desenvolvimento pessoal. O professor ao estabelecer com a criança uma relação de respeito e harmonia, não irá ver seu aluno como um depósito de informações e sim um sujeito pensante 
influente no seu meio social, escolar e familiar (Freire,1996, p. 52).

Dar oportunidade de participação para todos os alunos, o professor deve ser justo demonstrar confiança em suas habilidades não tomar decisões que favoreça um aluno em detrimento de outro, incentivar trabalhos em grupo, dar sugestão que ajude o autocontrole e a solução dos problemas, incentivar a calma, promover o exercício de democracia, desenvolver regras conjuntas e decidir com o grupo as consequências de comportamentos inadequados colegas (Lipp, 2000).

No processo de ensino aprendizagem é importante que a sala de aula seja organizada e atrativa, promovendo um efeito mental positivo nos alunos (LIPP 2000). Um dos procedimentos metodológicos indicados é a adoção das metodologias ativas, uma vez que por meio dela professores e alunos se envolvem ativamente no processo, estabelecendo trocas e ações conjuntas em prol da solução de problemas.

As contínuas e rápidas mudanças da sociedade contemporânea trazem exigências de um novo perfil docente. Daí a urgente necessidade de repensar a formação de professores, tendo como ponto de partida novas metodologias de ensino que contemple a diversidade dos saberes essenciais à prática docente, transpondo, assim, a racionalidade técnica de uma práxis instrumental para uma perspectiva que busque verdadeira inclusão de acordo com cada tipo de necessidade, valorizando os saberes já construídos, com base numa postura reflexiva, investigativa, crítica e tecnológica (Sousa; Alves, 2017).

O desafio para a educação não é apenas saber como ensinar ou como avaliar, mas apresentar o conhecimento em um formato que o cérebro aprenda de melhor e com mais facilidade, entendendo formas de investigar como se processa a aprendizagem, e como o mesmo se comporta neste processo (Diesel; Baldez; Martins, 2017).

De acordo com o mundo globalizado surge à necessidade de os docentes buscarem novos caminhos e novas metodologias de ensino que foquem no protagonismo dos estudantes, favoreçam a motivação e promovam a autonomia destes. Assim, atitudes como oportunizar a escuta aos estudantes, valorizar suas opiniões, exercitar a empatia, responder aos questionamentos, encorajá-los, dentre outras, são favorecedoras da motivação e da criação de um ambiente favorável à aprendizagem, sendo esta uma atividade social, na qual os alunos precisam de oportunidades para discutir tópicos em um ambiente tranquilo, prazeroso livre de agentes estressores (Berbel, 2011).

A formação de educadores não se limita a um aprendizado de técnicas educativas, mas avança no sentido de constituição dos sujeitos, o que torna essencial a criação de modos de ser e fazer por meio das metodologias ativas, tomadas como base para o planejamento de situações de aprendizagem que poderão contribuir de forma significativa para o desenvolvimento da autonomia e motivação do estudante à medida que favorece o sentimento de pertença e de coparticipação, tendo em vista que a teorização deixa de ser o ponto de partida e passa a ser o ponto de chegada, dado os inúmeros caminhos e possibilidades que a realidade histórica e cultural dos sujeitos procede (Bassalobre, 2013).

Quando trata-se da aprendizagem, existem alguns princípios e padrões comuns que podem ser adequados para todos, mas existem situações que são específicas individuais e resultantes da experiência vivida por cada um e que, o educador precisa conhecer para poder mediar de maneira diferenciada sabendo que cada criança é um ser único com características e peculiaridades próprias; há aquelas com maior facilidade de aprendizagem e outras que possuem maiores dificuldades, porém, tais dificuldades podem surgir até mesmo em crianças com altas habilidades cognitivas se elas estiverem expostas a situações que lhe causem desconforto, levando a crises de estresse, onde, por mais dedicada e inteligente que criança seja não conseguirá bons resultados de aprendizagem, lembrando que em decorrência do estresse excessivos a criança fica exposta a falta de atenção, memória, concentração, interesse, apatia ou agitação. Desta maneira o docente deve ter conhecimento das características individuais de seus alunos, mediando à situação, visando minimizar os sintomas e consequências do estresse e até mesmo auxiliar na recuperação de seu aluno (Lipp, 2008).

Toda metodologia de ensino e de aprendizagem parte de uma concepção de como o sujeito aprende, o professor atua como facilitador ou orientador para que o estudante faça pesquisas, reflita e decida por ele mesmo, o que fazer para atingir os 
objetivos estabelecidos, trata-se de um processo que oferece meios para que se possa desenvolver a capacidade de análise de situações com ênfase nas condições regionais e apresentar soluções em consonância com o perfil psicossocial da comunidade na qual se está inserido, pautados nas principais teorias de aprendizagem (Moreira, 2011).

Dessa forma, cada um, no seu percurso formativo, quer como estudante, quer como professor ou professora, age em consonância com as concepções de educação e de aprendizagem, portanto, faz-se necessário reflexões, com objetivo buscar pontos de convergência e aliar as metodologias ativas de ensino a abordagens já consagradas do âmbito da prática docente, voltadas para os processos de ensino e de aprendizagem pela interação social, Lev Vygotsky (1896-934), na aprendizagem pela experiência (Dewey, 1978), a aprendizagem significativa de David Ausubel (1918-2008) e levando em consideração a perspectiva freiriana da autonomia (Freire, 1996) humanização entre outros (Diesel; Baldez; Martins, 2017).

A utilização de metodologias ativas de ensino na formação inicial requer em exercício refletido dessa vivência fortalecendo uma prática docente mais consciente e efetiva, favorecendo a formação de sujeitos autônomos e, por conseguinte, a construção de uma educação com qualidade social para todos.

Sabe-se que no contexto de sala de aula, tanto docente quanto o discente sofrem pressões adversas o que pode trazer danos à saúde, pois diante desta realidade cabe ao professor desenvolver estratégia que possam amenizar ou até mesmo sanar este problema trabalhando em conjunto com os discentes, introduzindo coisas diferentes da rotina escolar, sendo possível fazer junção do que se tem a fazer referente a pratica escolar, com o que se gosta de fazer, sem que se deixe o aprendizado de lado alcançando assim equilibro emocional e bem estar em um convívio pacifico e equilibrado tanto para o docente como para o discente (Xavier; Chaves, 2013).

O fundamental é que o professor e alunos saibam que a postura deles, do professor e dos alunos, é dialógica, aberta, curiosa, indagadora e não apassivada, enquanto fala ou enquanto ouve. O que importa é que professor e alunos assumam-se epistemologicamente curiosos. Neste sentido, o bom professor é o que consegue, enquanto explica o conteúdo, trazer o aluno até a intimidade do movimento de seu pensamento. Sua aula é assim um desafio e não uma "cantiga de ninar". Seus alunos cansam, não dormem. Cansam porque acompanham as idas e vindas de seu pensamento, surpreendem suas pausas, suas dúvidas, suas incertezas (Freire, 1996, p.52).

Em sala de aula, tanto para o educador como para os educandos a pressão sofrida traz danos à saúde que podem ser amenizados ou até mesmo sanados se ambos trabalharem juntos, introduzindo algo diferente na rotina escolar. Os problemas pessoais podem estar presentes dentro de sala tanto pelo educador como pelo educando, havendo necessidade de maturidade e sensibilidade por parte do educando de buscar o lado positivo dos acontecimentos. Analisar as situações, aparentemente desfavoráveis, pelo ângulo da aprendizagem e crescimento pessoal. O ideal é que o professor insira no contexto de suas atividades educativas a visão de que as coisas têm seu lado positivo. Demonstrando que o ser humano pode conviver com seus problemas sem perder o bom humor (Yepes, 2002).

\section{Considerações Finais}

Pudemos observar no decorrer do artigo que o estresse infantil é um transtorno que rações no organismo frente a situações muito difíceis ou muito excitantes, podendo ocorrer em crianças de qualquer idade, independentemente do sexo. Ele pode manifestar-se por meio de sintomas físicos ou psicológicos podendo interferir na capacidade de reter informações em relações afetivas e sociais.

Esse estresse pode ser proveniente de diferentes causas, destacando-se como principais fontes geradoras de estresse infantil situações ocorridas no ambiente familiar e escolar, considerando cobranças excessivas para determinadas idades, onde a criança sai do convívio familiar e tem a escola como o primeiro lugar socializante, com um importante papel na construção do sujeito, em seu aprendizado e inserção na sociedade, havendo necessidade de adaptação. 
Deste modo, para minimizar os sintomas e consequências do estresse no processo de ensino e aprendizagem é necessário que a intervenção do professor busque oportunizar um ambiente harmonioso, que permita a seus alunos aprenderem de forma tranquila e significativa, porque nesse período os processos afetivos e a estabilidade emocional de maneira positiva ampliam na criança o interesse pela aprendizagem de maneira saudável, proporcionando experiências que auxiliam no desenvolvimento das capacidades cognitivas, atenção, memoria, raciocínio e bem estar.

Crianças que possuem professores que promovem o ensino de técnicas de manejo do estresse, adicionadas a metodologias ativas serão mais bem preparadas em relação às adversidades da vida. Deste modo o professor é peça-chave no desenvolvimento da criança e deve zelar pelo seu bem-estar e sempre buscar a melhor forma de relacionar-se com seus alunos e desenvolver suas aulas, para que está não se torne mais uma fonte de estresse em que os alunos estejam submetidos.

$\mathrm{O}$ estresse infantil reflete-se no processo de ensino e de aprendizagem, em especial nos primeiros anos da educação básica, uma vez que a criança com dificuldade de aprendizagem não apresenta somente esta dualidade especifica, mas também convive com sentimento de insegurança, medo baixa autoestima podendo comprometer seu desenvolvimento, havendo necessidade de uma relação cultivada de afeto respeito entre professor e aluno, acarretando em confiança e segurança que o aluno terá em superar suas dificuldades de aprendizagem e desenvolvimento pessoal.

Diante dos indicativos do presente estudo, indica-se que novas pesquisas sejam realizadas em relação a temática e busque verificar junto a pais e educadores como o processo de ensino e aprendizagem pode causar estresse nos alunos na educação infantil e quais os principais reflexos deste no processo de ensino e de aprendizagem.

\section{Referências}

Bartholomeu, D., Sisto, F. F., \& Marin Rueda, F. J. (2006). Dificuldades de aprendizagem na escrita e características emocionais de crianças. Psicologia em estudo, 11, 139-146. https://doi.org/10.1590/S1413-73722006000100016

Bassalobre, J. N. (2013). Ética, responsabilidade social e formação de educadores. Educação em Revista, 29, 311-317. https://doi.org/10.1590/S010246982013000100013

Berbel, N. A. N. (2011). As metodologias ativas e a promoção da autonomia de estudantes. Semina: Ciências sociais e humanas, 32(1), 25-40. https://doi.org/10.5433/1679-0359.2011v32n1p25

Brasil (1996). Ministério de Educação e Cultura. LDBEN- LEI 9394/96. MEC.

Coll, C., \& Bolea, E. (1996). As intenções educativas e os objetivos da educação escolar: alternativas e fundamentos psicológicos. Coll, C. et al. Desenvolvimento psicológico e educação: psicologia da educação. Tradução de Angélica Mello Alves. Artes Médicas, 19, $317-32$.

Conforto, E. C., Amaral, D. C., \& Silva, S. D. (2011). Roteiro para revisão bibliográfica sistemática: aplicação no desenvolvimento de produtos e gerenciamento de projetos. Trabalho apresentado, 8. Congresso Brasileiro de Gestão de desenvolvimento de Produto.

Costa, S. F. P. (2011). Dificuldades de Aprendizagem. Revista Profissão Docente, 11(23), 155-158.

de Oliveira, L. L., de Carvalho, L. M. A., Cardoso, N. V., dos Santos, M. C. Q., Lins, B. S., \& Ramos, T. T. O. (2020). Práticas pedagógicas ativas e participativas com a metodologia Intervalo com Saberes e Sabores: relato de experiência. Research, Society and Development, 9(9), e452997465-e452997465. https://doi.org/10.33448/rsd-v9i9.7465

da Silva Braga, N. P., \& Rodrigues, A. (2020). Ser e estar professor na educação infantil: significações em movimento. Research, Society and Development, 9(4), e32942735-e32942735. https://doi.org/10.33448/rsd-v9i4.2735

de Souza, A. J. M., Freire, A. I., de Souza, F. B. M., \& De Araujo, E. G. (2020). Revisitando a hipótese de Bowlby: teoria do apego, maturação neuroendócrina e predisposição para psicopatologias. Research, Society and Development, 9(11), e3579119895-e3579119895. https://doi.org/10.33448/rsd-v9i11.9895

Dewey, J. (1978). Democracia e educação: introdução à filosofia da educação. Companhia Editora Nacional.

Diesel, A., Baldez, A. L. S., \& Martins, S. N. (2017). Os princípios das metodologias ativas de ensino: uma abordagem teórica. Revista Thema, 14(1), 268-288. https://doi.org/10.15536/thema.14.2017.268-288.404

Dos Santos, F. H., Andrade, V. M., \& Bueno, O. F. (2015). Neuropsicologia hoje. Artmed Editora.

Elkind, D. (2004). Sem tempo para ser criança: a infância estressada. (3a ed.), Art méd.

Ferreira, A. B. H (2010). Dicionário Aurélio da língua portuguesa. (5a ed.), Positivo.

Freire, P. (1996). Pedagogia da Autonomia. (28a ed.), Editora Paz e Terra. 
Fuentes, D., Malloy-Diniz, L. F., de Camargo, C. H. P., \& Cosenza, R. M. (2014). Neuropsicologia-: Teoria e Prática. Artmed Editora.

Gil, A. C. (2002). Como elaborar projetos de pesquisa (Vol. 4, p. 175). Atlas.

Gonçalves, L. C. S., Canal, C. P. P., \& Missawa, D. D. A. (2016). Investigação sobre estresse em crianças com dificuldade de aprendizagem. Construção psicopedagógica, 24(25), 149-169.

Kraemer, M (2010. Aprendendo com criatividade. Autores Associados, 2010.

Lipp, M. E. N., Souza, E. A. P. D., \& Romano, A. S. P. F. (1991). Como enfrentar o stress infantil. In Como enfrentar o stress infantil (pp. 93-93).

Lipp, M. E. N.; \& Lucarelli, M. D. M (2008). Manual da escala de stress infantil-ESI. Casa do Psicólogo 2008.

Lipp, M. E. N.; \& Romano, A. S. F (2000). O stress infantil. Estudos de psicologia, 4(2), 42-54.

Lipp, M. E. N., Arantes, J. P., Buriti, M. D. S., \& Witzig, T. (2002). O estresse em escolares. Psicologia escolar e educacional, 6, 51-56. https://doi.org/10.1590/S1413-85572002000100006

Molina, O. F (1996). Estresse no cotidiano. Pancast, 1996.

Moreira, M. A. (2011). Abandono da narrativa, ensino centrado no aluno e aprender a aprender criticamente. Ensino, Saúde e Ambiente, 4(1).

Nascimento, m. L., campos, m. M., \& coelho, r. (2011). As políticas e a gestão da educação infantil. Revista Retratos da Escola, Brasília, 5(9), $201-214$.

Nery, M. P (2003). Vínculo e afetividade. Àgora.

Neves, M.C, \& Carvalho, C. (2006). A importância da afectividade na aprendizagem da matemática em contexto escolar: Um estudo de caso com alunos do 8 o $^{\circ}$ ano. Análise Psicológica, 24(2), 201-215. https://doi.org/10.14417/ap.164

Prodanov, C. C., \& Freitas, E. D. (2013). Metodologia do trabalho científico [recurso eletrônico]: métodos e técnicas da pesquisa e do trabalho acadêmico. (2a ed.), Feevale.

Saviani, D. (1985). Sentido da pedagogia e papel do pedagogo. Revista da ANDE, (9), 27-28.

Sisto, F. F., \& Martinelli, S. D. C. (2006). O papel das relações sociais na compreensão do fracasso escolar e das dificuldades de aprendizagem. A afetividade $e$ dificuldades de aprendizagem, 13-30.

Sousa, A. M. O. P. D., \& Alves, R. R. N. (2017). A neurociência na formação dos educadores e sua contribuição no processo de aprendizagem. Revista Psicopedagogia, 34(105), 320-331.

Tomaz, C., \& Giugliano, L. G. (1997). A razão das emoções: um ensaio sobre" O erro de Descartes". Estudo de Psicologia. 2 (2).

Tunes, E., Tacca, M. C. V., \& Bartholo Júnior, R. D. S. (2005). O professor e o ato de ensinar. Cadernos de pesquisa, 35, 689-698. https://doi.org/10.1590/S010015742005000300008

Vygotsky, L. S., Luria, A. R.; \& Leontiev, A. N (1988). Linguagem, desenvolvimento e aprendizagem. Ícone.

Wallon, H (2007). A evolução psicológica da criança. Martins Fontes,

Xavier, J. M., \& Chaves, M. A. (2013). O estresse no processo educativo. Revista Saberes da UNIJIPA 1(1).

Yepes, H. D (2002). Como Prevenir e Controlar o Estresse: Síndrome do Século XXI. (2a ed.), Paulinas. 